\title{
Pengaruh Store Atmosphere, Etika Bisnis dan Kualitas Produk Terhadap Kepuasan Konsumen
}

\author{
Dahmiri $^{1}$, Sylvia Kartika wulan Bhayangkari ${ }^{2}$ \\ ${ }^{1,2}$ Program Studi Manajemen FEB Universitas Jambi \\ Correspondence Email: dahmiri@unja.ac.id
}

\begin{abstract}
This study aims to analyze the influence of the influence of store atmosphere, business ethics and product quality on consumer satisfaction at the syariah syariah mini market 212 Jambi branch. Survey research using a questionnaire instrument, a sample of 70 respondents with nonprobability sampling techniques. Data analysis uses multiple linear regression. The results of the study concluded that the characteristics of respondents were dominated by women, aged 20 to 29 years, the last education occupations were dominated by students. Simultaneously store atmosphere, business ethics and product quality have a positive and significant effect on customer satisfaction, so also partially store atmosphere variables, business ethics and product quality have a positive and significant effect on customer satisfaction.
\end{abstract}

Keywords: store atmosphere, business ethics, product quality, customer satisfaction

\section{Pendahuluan}

Perekonomian Indonesia terus mengalami perubahan di segala bidang sejalan dengan perkembagnan ekonomi global. Perubahan tersebut antara lain dipengaruhi oleh berbagai faktor diantaranya perilaku konsumen, kebijakan pemerintah, persaingan bisnis, perkembangan ilmu pengetahuan dan teknologi serta arus komunikasi yang berkembang semakin cepat. Perkembangan ekonomi baik secara nasional maupun global dapat menjadi peluang sekaligus ancaman bagi pelaku usaha dalam mempertahankan dan mengembangkan usaha. Menyikapi persaingan usaha ritel yang semakin ketat saat ini seorang pengusaha pengusaha harus mampu menciptakan keunggulan dari berbagai aspek bisnis agar mampu bertahan dan mengembangkan usaha. Diantara keunggulan yang dapat dihadirkan antara lain berkaitan dengan store atmosphere, etika bisnis dan kualitas produk. Store atmosphere adalah suasana toko yang meliputi penataan ruang sebaik mungkin untuk menciptakan suasana yang nyaman saat konsumen berbelanja. Etika bisnis merupakan seperangkat nilai tentang baik dan buruk, benar dan salah dalam dunia bisnis berdasarkan pada prinsip-prinsip moralitas. kualitas produk adalah kemampuan suatu produk dalam melaksanakan fungsi dan kinerjanya yang dapat memenuhi kebutuhan dan keinginan pelanggan.

Survey pendahuluan yang dilakukan pada Mini Market Syariah 212 Cabang Jambi diperoleh informasi bahwa toko ini telah menerapkan store atmosphere, etika bisnis dan menghadirkan produk yang berkualitas. Namun demikian belum diketahui apakah uapay yang telah dilakukan tersebut mempengaruhi kepuasan konsumen atau tidak serta berapa besar pengaruhnya, karena belum pernah ada kajian atau penelitian yang menelaah hal ini.

Penelitian terdahulu tentang variable store atmosphere, etika bisnis, kualitas produk dan kepuasan kosumen sudah banyak dilakukan baik pada skala global maupun nasional. Hasil penelitian sebagian besar menyimpulkan bahwa store atmosphere, etika bisnis dan kualitas produk berpengaruh terhadap kepuasan kosumen (Miswanto, M., \& Angelia, Y. R. (2017); Van Niekerk, B. (2015); Widyartono, A., Sarjono, A., \& Tyra, M. J. (2017); Aunti Sholihah, F., \& Indrarini, R. (2019); Hoe, L. C., \& Mansori, S. (2018); Cruz, A. V. (2015); Olise, Chigbata M, Christian O.O. (2018). Tujuan penelitian adalah untuk menganalisis pengaruh store atmosphere, etika bisnis dan kualitas produk terhadap kepusan konsumen pada Mini Market Syariah 212 Cabang Jambi baik secara simultan maupun secara parsial.

\section{Store Atmosphere}

Store atmosphere merupakan kombinasi dari karakteristik fisik seperti arsitektur, tata letak (display), pencahayaan, warna, temperatur, musik, serta aroma yang bertujuan meransang respon emosional dan persepsi pelanggan dan untuk mempengaruhi pelanggan dalam membeli barang atau produk (Purnomo, A. K., 2017). Menurut Zentes, J., Morschett, D., \& SchrammKlein, H. (2007) dan Evans, J. R., \& Berman, B. (2005), terdapat elemen store atmosphere yang berpengaruh yang terditi dari Exterior, General Interior, Store Layout dan Interior Display . Adapun keempat elemen tersebut akan dijelaskan lebih lengkap sebagai berikut:

a. Exterior, karakteristik exterior mempunyai pengaruh yang kuat pada citra toko tersebut, sehingga harus direncanakan dengan sebaik mungkin. Kombinasi dari exterior ini dapat membuat bagian luar toko menjadi terlihat unik, menarik, menonjol dan mengundang orang untuk masuk kedalam toko.

b. General Interior, paling utama yang dapat membuat penjualan setelah pembeli berada di toko adalah display. Desain interior dari suatu toko harus dirancang untuk memaksimalkan visual 
merchandising. Display yang baik yaitu dapat menarik perhatian pengunjung dan membantu mereka agar mudah mengamati, memeriksa dan memilih barang dan akhirnya melakukan pembelian.

c. Layout Ruangan, pengelola toko harus mempunyai rencana dalam penentuan lokasi dan fasilitas toko. Pengelola toko juga harus memanfaatkan ruangan toko yang ada seefektif mungkin.

d. Interior Point of Interest Display, mempunyai dua tujuan, yaitu memberikan informasi kepada konsumen dan menambah store atmosphere ,hal ini dapat meningkatkan penjualan dan laba toko.

\section{Etika Bisnis}

Etika bisnins menurut Fahmi, I. (2013) adalah analisis dan penerapan konsep seperti benar, salah, baik, buruk, dan tanggung jawab. Etika adalah ilmu yang berkenaan tentang yang buruk dan tentang hak dan kewajiban moral. Menurut Wijayakusuma, K. M., dan Yusanto, I., M. (2003) bisnis adalah suatu aktivitas yang mengarahkan pada peningkatan nilai tambah melalui proses penyerahan jasa, perdagangan atau pengolahan barang (produksi). Bisnis selalu bergerak mencari keunggulan kompetitif, dan salah satu keunggulan kompetitif bisa diperoleh pelaku bisnis dengan menonjolkan etika dalam perilaku bisnisnya. Selain keunggulan kompetitif yang dikejar oleh pelaku bisnis, memperoleh relasi bisnis yang dapat dipercaya juga salah satu tujuan pelaku bisnis. Komitmen moral, disiplin, loyalitas, kerja sama, integritas pribadi, tanggung jawab, dan kejujuran sangat diperlukan dalam menjalankan aktivitas bisnis (Sunyoto, D. (2012)).

\section{Kualitas produk}

Menurut Kotler, P., \& Gary, A. (2016) kualitas produk merupakan kemampuan suatu produk dalam melaksanakan fungsi dan kinerjanya yang dapat memenuhi kebutuhan dan keinginan pelanggan. Dimensi kualitas produk terdiri dari:

1. Kinerja (performance), yaitu karakteristik operasi pokok dari produk inti.

2. Ciri-ciri atau keistimewaan tambahan (features), yaitu karakteristik sekunder atau pelengkap.

3. Kehandalan (reliability), yaitu kemungkinan kecil akan mengalami kerusakan atau gagal pakai.

4. Kesesuaian dengan spesifikasi (conformance to specification), yaitu sejauh mana karakteristik desain dan operasi memenuhi standar-standar yang telah ditetapkan sebelumnya.

5. Daya tahan (durability), yaitu berkaitan dengan berapa lama produk tersebut dapat terus digunakan.

6. Serviceability, meliputi kecepatan, kompetensi, kenyamanan, mudah direparasi, penanganan keluhan yang memuaskan.

7. Estetika, yaitu daya tarik produk terhadap panca indera.

\section{Kepuasan Konsumen}

Kepuasan konsumen adalah tingkat perasaan seseorang setelah membandingkan kinerja (atau hasil) yang ia rasakan dibandingkan dengan harapannya (Kotler, P., \& Gary, A. (2016). Menurut Tjiptono, F. (2018), adalah perasaan senang atau kecewa yang berasal dari perbandingan antara kesannya terhadap kinerja atau hasil suatu produk dan harapan-harapannya. Kepuasan konsumen akan diperoleh jika kinerja suatu produk dapat memenuhi atau melebihi harapan konsumen dan konsumen merasa tidak puas jika kinerja suatu produk kurang dari yang diharapkan konsumen (Kristianto P.L., 2011). Kepuasan konsumen adalah persepsi konsumenbahwa bahwa harapannya telah terpenuhi atau terlampaui dengan membeli atau menggunakan produk tersebut (Wijayanti, T., 2017). Indikator kepuasan konsumen menurut Tjiptono, F. (2018), mengukur kepuasan konsumen terdiri dari:

1. Kesesuaian harapan, merupakan tingkat kesesuaian antara kinerja produk yang diharapkan konsumen dengan yang dirasakan oleh konsumen

2. Minat berkunjung kembali, merupakan kesediaan konsumen untuk berkunjung kembali atau melakukan pembelian uang terhadap produk terkait.

3. Kesediaan merekomendasikan, merupakan kesediaan konsumen untuk merekomendasikan produk yang telah dirasakannya kepada teman atau keluarga

\section{Metode}

Populasi adalah wilayah generalisasi yang terdiri dari subjek dan objek yang mempunyai karateristik dan kualitas tertentu untuk dipelajari kemudian ditarik kesimpulannya. Populasi penelitian ini adalah seluruh konsumen toko selama Tahun 2019 yang jumlahnya tidak diketahui secara pasti.Sampel adalah bagian dari jumlah dan karakteristik yang dimiliki oleh populasi tersebut (Sugiyono, H., 2016). Sampel dalam penelitian ini berjumlah 100 orang yang ditentukan dengan rumus Slovin. Jenis data yaitu data primer dan data sekunder. Data primer diperoleh dari kuesioner yang disampaikan kepada responden, sedangkan data sekunder diperoleh dari Mini Market syariah 212 cabang Jambi. Metode analisis yang digunakan adalah analisis deskriptif dan analisis regresi linier berganda dengan softwere SPSS, yang meliputi uji simultan (uji F), uji parsial (uji t) dan uji koefisien determinasi $\left(\mathrm{R}^{2}\right)$. Sebelum dilakukan analisis regresi linier berganda dilakukan uji instrument penelitian berupa uji validitas dan uji reliabilitas. Persamaan regresi pada penelitian ini dapat dirumuskan sebagai berikut:

$\mathrm{Y}=\mathrm{a}+\beta 1 \mathrm{X} 1+\beta 2 \mathrm{X} 2+\beta 3 \mathrm{X} 3+\mathrm{e}$

dimana: $\mathrm{Y}=$ Kepuasan konsumen; $\mathrm{a}=$ Konstanta; $\beta 1$, $\beta 2, \beta 3=$ Koefisien Regresi; $X_{1}=$ Store Atmosphere; $X_{2}=$ Etika bisnis; $\mathrm{X}_{3}=$ Kualitas Produk; $\mathrm{e}=$ error 


\section{Hasil}

Hasil Uji validitas memperoleh hasil bahwa Pearson Corelation-nya lebih besar dari 0,3, sehingga dapat disimpulkan semua item pernyataan yang digunakan dalam penelitian ini dinyatakan valid dan semua item menujukkan arah yang positif. Uji realibilitas yang dilakukan dengan korelasi Spearman
Brown diperoleh hasil semua item pernyataan dinyatakan reliabel, karena nilai Croanbach's Alpha di atas 0,6 . Pengujian terhadap pengaruh store atmosphere $\left(\mathrm{X}_{1}\right)$, etika bisnis $\left(\mathrm{X}_{2}\right)$ dan kualitas produk $\left(\mathrm{X}_{3}\right)$ terhadap kepuasan konsumen (Y), digunakan regresi linier berganda dan juga untuk menguji hipotesis.

Tabel 1

Model Summary

\begin{tabular}{c|r|r|r|r}
\hline Model & R & \multicolumn{1}{|c|}{ R Square } & Adjusted R Square & \multicolumn{2}{c}{ Std. Error of the Estimate } \\
\hline 1 & $.548^{\mathrm{a}}$ & .432 & .576 & 1.11210 \\
\hline
\end{tabular}

Sumber: data olahan

Hasil analisis regresi linier berganda diketahui bahwa nilai $\mathrm{R}=0,548$. Hal ini berarti bahwa hubungan store atmosphere, etika bisnis dan kualitas produk dan kepuasan konsumen sebesar 54,8\%. Artinya hubungannya erat. Adjusted $\mathrm{R}$ square sebesar 0,576 berarti 57,6 \% variable kepuasan konsumen Mini Market
Syariah 212 Cabang Jambi dapat dijelaskan oleh store atmosphere, etika bisnis dan kualitas produk, sedangkan $42,4 \%$ dijelaskan oleh variabel lain diluar penelitian ini.

\section{Uji Simultan}

Tabel 2

Anova

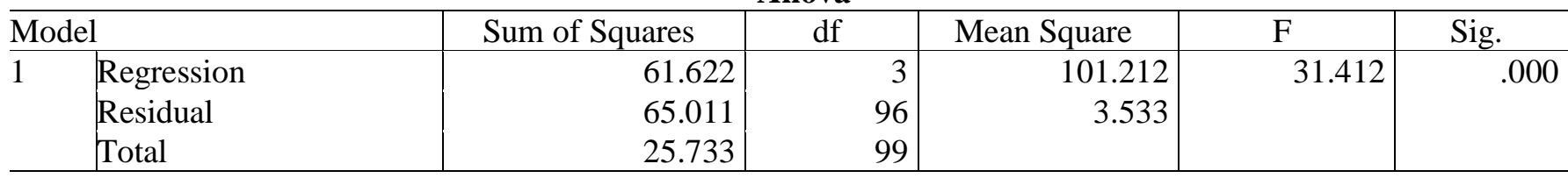

Sumber: data olahan

Tabel diatas dapat dilihat nilai $\mathrm{F}$ hitung adalah sebesar 31,412 dengan nilai signifikansi F sebesar 0.000. Jika dibandingkan dengan taraf signifikansi $\alpha=0.05$ maka $p$-value $(0.000)$ bernilai lebih kecil dari $\alpha$ $(0.000<0.05)$, sehingga $\mathrm{H}_{0}$ diterima $\mathrm{H}_{\mathrm{a}}$ ditolak, yaitu terdapat pengaruh yang signifikan secara simultan $\mathrm{X}_{1}=$ store atmosphere, $\mathrm{X}_{2}=$ etika bisnis dan $\mathrm{X}_{3}=$ kualitas produk terhadap $\mathrm{Y}=$ kepuasan konsumen Mini Market Syariah 212 Cabang Jambi .

Tabel 3

Uji Parsial

\begin{tabular}{l|l|r|r|r|r|r}
\hline \multicolumn{2}{l|}{} & $\mathrm{B}$ & Std. Error & Beta & $\mathrm{t}$ & \\
\hline 1 & (Constant) & .164 & .302 & & .455 & .613 \\
& Store atmosphere & .463 & .121 & .316 & 2.819 & .000 \\
& Etika bisnis & .366 & .11 & .444 & 2.943 & .000 \\
& Kualitas produk & .454 & .180 & .253 & 2.532 & .002 \\
\hline
\end{tabular}

Sumber: data olahan

a. Variabel Store atmosphere $\left(\mathrm{X}_{1}\right)$ berpengaruh positif dan signifikan terhadap kepuasan konsumen (Y), hal ini terlihat dari nilai signifikan $0,000<0,05$, maka $\mathrm{H}_{0}$ ditolak dan menerima $\mathrm{H}_{\mathrm{a}}$, berarti variabel independen $\left(\mathrm{X}_{1}\right)$ secara parsial mempunyai pengaruh yang signifikan terhadap variabel dependen $(\mathrm{Y})$.

b. Variabel etika bisnis $\left(\mathrm{X}_{2}\right)$ berpengaruh positif dan signifikan terhadap kepuasan konsumen $(\mathrm{Y})$, hal ini terlihat dari nilai signifikan $0,000<0,05$, maka $\mathrm{H}_{0}$ ditolak dan menerima $\mathrm{H}_{\mathrm{a}}$, berarti variabel independen $\left(\mathrm{X}_{1}\right)$ secara parsial mempunyai pengaruh yang signifikan terhadap variabel dependen (Y). c. Variabel kualitas produk $\left(\mathrm{X}_{3}\right)$ berpengaruh positif dan signifikan terhadap kepuasan konsumen (Y), hal ini terlihat dari nilai signifikan $0,002<0,05$, maka $\mathrm{H}_{0}$ ditolak dan menerima $\mathrm{H}_{\mathrm{a}}$, berarti variabel independen $\left(\mathrm{X}_{1}\right)$ secara parsial mempunyai pengaruh yang signifikan terhadap variabel dependen (Y).

d. Berdasarkan hasil output tesebut, maka rumus persamaan regresinya adalah :

$Y=\beta_{0}+\beta_{1} X_{1}+\beta_{2} X_{2}+\beta_{3} X_{3}+e_{i}$ $\mathrm{Y}=0.164+0.463 \mathrm{X}_{1}+0.366 \mathrm{X}_{2}+0.454 \mathrm{X}_{3}+\mathrm{e}_{\mathrm{i}}$ 


\section{Pembahasan}

Penelitian ini bertujuan untuk menganalisis pengaruh store atmosphere, etika bisnis dan kualitas produk terhadap kepuasan konsumen pada Mini Market Syariah 212 Cabang Jambi. Hasil analisis diperoleh data bahwa nilai $\mathrm{R}$ menunjukkan hubungan erat antara variabel independen $\left(\mathrm{X}_{1}, \mathrm{X}_{2}, \mathrm{X}_{3}\right)$ dengan variabel dependen (Y) sebesar 0,613. Hubungannya dikatakan erat karena nilai $\mathrm{R}$ mendekati 1 , tanda positif dari nilai $\mathrm{R}$ berarti nilai $R$ variabel independen tersebut mempunyai hubungan searah dengan variabel dependen, jika variabel independen ditingkatkan maka variabel dependen juga akan meningkat, begitu pula sebaliknya. Adjusted R square sebesar 0,576 berarti 57,6 \% variabel kepuasan konsumen dapat dijelaskan oleh variabel store atmosphere, etika bisnis dan kualitas produk, sedangkan $42,4 \%$ dapat dijelaskan oleh variabel lain di luar penelitian ini. Variabel store atmosphere, etika bisnis dan kualitas produk secara simultan berpengaruh signifikan terhadap variabel kepuasan konsuemen Mini Market Syariah 212 Cabang Jambi (Y). Hal ini dapat dilihat dari taraf signifikansi lebih kecil dari $\alpha$ $(0,000<0,05)$, sehingga $\mathrm{H}_{0}$ diterima $\mathrm{H}_{1}$ ditolak, yaitu terdapat pengaruh yang signifikan secara simultan $\mathrm{X}_{1}=$ store atmosphere, $\mathrm{X}_{2}=$ etika bisnis dan $\mathrm{X}_{3}=$ kualitas produk terhadap $\mathrm{Y}=$ kepuasan konsumen.

Pengujian secara parsial menunjukkan angka positif pada variabel store atmosphere, etika bisnis dan kualitas produk, sehingga dapat katakan bahwa secara parsial semua variable independen mempunyai pengaruh signifikan terhadap kepuasan konsumen Mini Market Syariah 212 Cabang Jambi. Apabila variabel store atmosphere, etika bisnis dan kualitas produk ditingkatkan secara parsial, maka kepuasan konsumen juga akan meningkat. Variabel yang berpengaruh dominan terhadap keputusan berkunjung adalah variable store atmosphere dengan koefisien regresi $(\beta)$ sebesar 0,463 . Hasil penelitian ini sejalan dengan beberapa penelitian terdahulu yang pernah dilakukan dimana variabel store atmosphere berpengaruh terhadap kepuasan konsumen, seperti penelitian yang dilakukan oleh Putri, L. H. (2014); Miswanto, M., \& Angelia, Y. R. (2017); Van Niekerk, B. (2015); Diawan, N. S., Kusumawati, A., \& Mawardi, M. K. (2016). Adapun hasil penelitian yang sejalan dengan penelitian ini tentang pengaruh etika bisnis terhadap kepuasan konsumen antara lain penelitian oleh Fauzan, F., \& Nuryana, I. (2014); Widyartono, A., Sarjono, A., \& Tyra, M. J. (2017); Aunti Sholihah, F., \& Indrarini, R. (2019); Lestari, Z. (2015); Rosiyana, L., Arifin, Z., \& Sunarti, S. (2017. Sedangkan penelitian tentang pengaruh kualitas produk terhadap kepuasan konsumen yang menghasilkan kesimpulan yang sama antara lain penelitian oleh Miswanto, M., \& Angelia, Y. R. (2017); Hoe, L. C., \& Mansori, S. (2018); Razak, I., Nirwanto, N., \& Triatmanto, B. (2016); Wantara, P., \& Tambrin,
M. (2019); Cruz, A. V. (2015); Jahanshahi, A. A., Gashti, M. A. H., Mirdamadi, S. A., Nawaser, K., \& Khaksar, S. M. S. (2011); Kusuma, N. P. (2014); Olise, Chigbata M, Christian O.O. (2018); Sitanggang, J. M., Sinulingga, S., \& Fachruddin, K. A. (2019).

Persamaan penelitian ini dengan penelitian sebelumnya antara lain dari sisi variabel penelitian, dimana secara parsial variabel store atmosphere, etika bisnis dan kualitas produk sudah banyak dilakukan. Dilihat dari perbedaan dari penelitian sebelumnya antara lain dari aspek lokasi dan variable, dimana penelitian yang fokus pada toko ritel syariah belum banyak dilakukan baik di luar negeri maupun di Indonesia dengan berbagai variabel, demikian juga objek penelitian toko ritel syariah di Jambi masih sedikit dilakukan.

\section{Simpulan}

Variabel store atmosphere $\left(\mathrm{X}_{1}\right)$, etika bisnis $\left(\mathrm{X}_{2}\right)$ dan kualitas produk $\left(\mathrm{X}_{3}\right)$ berpengaruh signifikan terhadap variabel kepuasan konsumen (Y) Mini Market Syariah 212 Cabang Jambi, baik secara simultan maupun secara parsial. Variabel yang lebih dominan mempengaruhi keputusan berkunjung adalah variable store atmosphere. Jika ketiga variable independent ditingkatkan maka variable dependen juga akan meningkat. Kepada pemilik dan karyawan Mini Market Syariah 212 Cabang Jambi disarnkan untuk meningkatkan store atmosphere, etika bisnis dan kualitas produk yang sudah diterapkan supaya lebih meningkatkan kepuasan konsumen. Penelitian ini hanya berkonsentrasi pada variabel store atmosphere, etika bisnis dan kualitas produk, oleh karena itu kepada peneliti selanjutnya untuk melakukan penelitian tentang variabel-variabel lain dan objek berbeda agar menghasilkan penelitian yang lebih baik. Setelah mengetahui bahwa variabel yang lebih dominan mempengaruhi keputusan berkunjung adalah varibel store atmosphere, pemilik dan karyawan Mini Market Syariah 212 Cabang Jambi agar dapat meningkatkan store atmosphere guna mempertahankan dan meningkatkan kepuasan konsumen.

\section{Daftar Pustaka}

Aunti Sholihah, F., \& Indrarini, R. (2019). Pengaruh Persepsi Pelanggan Terkait Etika Bisnis Islam Terhadap Kepuasan Pelaggan Pengguna Ecommerce. Jurnal Ekonomi Islam, 2(3).

Cruz, A. V. (2015). Relationship Between Product Quality And Customer Satisfaction.

Diawan, N. S., Kusumawati, A., \& Mawardi, M. K. (2016). The Influence Of Store Atmosphere On Purchase Decision And It's Impact On Customer's Satisfaction (Case study on Indomaret Customers JL. Raya Tlogomas No. 37, Malang). Jurnal Administrasi Bisnis, 30(1), 8-16. 
Evans, J. R., \& Berman, B. (2005). Marketing in the 21st Century. Atomic Dog Publishing, Cincinnati, $\mathrm{OH}$.

Fahmi, I. (2013). Etika Bisnis. Alfabeta. Bandung.

Fauzan, F., \& Nuryana, I. (2014). Pengaruh Penerapan Etika Bisnis terhadap Kepuasan Pelanggan Warung Bebek H. Slamet di Kota Malang. Jurnal Ekonomi Modernisasi, 10(1), 38-55.

Hoe, L. C., \& Mansori, S. (2018). The Effects Of Product Quality On Customer Satisfaction And Loyalty: Evidence From Malaysian Engineering Industry. International Journal of Industrial Marketing, 3(1), 20-35.

Jahanshahi, A. A., Gashti, M. A. H., Mirdamadi, S. A., Nawaser, K., \& Khaksar, S. M. S. (2011). Study the effects of customer service and product quality on customer satisfaction and loyalty. International Journal of Humanities and Social Science, 1(7), 253-260.

Kotler, P., \& Gary, A. (2016). Prinsip-Prinsip Pemasaran (Bob Sabran, Penerjemah). Jakarta: Erlangga.

Kristianto, P. L. (2011). Integrasi Ilmu Psikologi Dalam Kegiatan Pemasaran. . Yogyakarta: CAPS.

Kusuma, N. P. (2014). Analyzing The Effect Of Product Quality On Customer Satisfaction And Customer Loyalty In Indonesian SMEs (Case Study on the Customer of Batik Bojonegoro Marely Jaya). Jurnal Administrasi Bisnis, 14(1).

Lestari, Z. (2015). Pengaruh Penerapan Etika Bisnis Islam Terhadap Kepuasan Anggota (Studi pada BMT KUBE Sejahtera Sleman).

Miswanto, M., \& Angelia, Y. R. (2017). The Influence Of Service Quality And Store Atmosphere On Customer Satisfaction. Jurnal Manajemen dan Kewirausahaan, 19(2), 106-111.

Olise, Chigbata M, Christian O.O. (2018). Effects of Product Quality on Customer Satisfaction: A Review of Manufacturing Company's Performance in Anambra State. International Journal of Business \& Law Research 6(1):3947.

Purnomo, A. K. (2017). Pengaruh Cafe Atmosphere Terhadap Keputusan Pembelian Gen Y Pada Old Bens Cafe. Jurnal Manajemen Maranatha, 16(2), 133-144.

Putri, L. H. (2014). Pengaruh Store Atmosphere Terhadap Keputusan Pembelian Dan Kepuasan Pelanggan (Studi pada Monopoli Cafe and Resto Soekarno Hatta Malang). Jurnal Administrasi Bisnis, 15(2).

Razak, I., Nirwanto, N., \& Triatmanto, B. (2016). The Impact Of Product Quality And Price On Customer Satisfaction With The Mediator Of Customer Value. Journal of Marketing and Consumer Research, 30(1), 59-68.
Rosiyana, L., Arifin, Z., \& Sunarti, S. (2017). Implementasi Etika Bisnis Islam Guna Membangun Bisnis Yang Islami (Studi pada Waroeng Steak And Shake Cabang Malang). Jurnal Administrasi Bisnis, 53(1), 196-201.

Sitanggang, J. M., Sinulingga, S., \& Fachruddin, K. A. (2019). Analysis of the Effect of Product Quality on Customer Satisfaction and Customer Loyalty of Indihome ATPT Telkom: Regional 1 Sumatera, Medan, North Sumatra, Indonesia. American International Journal of Business Management (AIJBM, 2(3), 26-37.

Sugiyono, H. (2016). Metode kualitatif dan kuantitatif. Cetakan ke-23. Alfabeta, Bandung.

Sunyoto, D. (2012). Dasar-dasar manajemen pemasaran. Yogyakarta: Caps.

Tjiptono, F. (2018). Strategi pemasaran. Andi.

Van Niekerk, B. (2015). The Influence Of Boutique Store Atmosphere On Customer Satisfaction, Store Loyalty And Repurchase Intention (Doctoral dissertation).

Wantara, P., \& Tambrin, M. (2019). The Effect of Price and Product Quality Towards Customer Satisfaction and Customer Loyalty on Madura Batik. International Tourism and Hospitality Journal, 2(1), 1-9.

Widyartono, A., Sarjono, A., \& Tyra, M. J. (2017). Pengaruh Keuramaan Etika Bisnis Terhadap Kepuasan Pelanggan Rumah Makan Pempek Di Palembang. Jurnal Keuangan Dan Bisnis, 15(2), 17-36.

Wijayakusuma, K. M., dan Yusanto, I., M. (2003). Pengantar Manajemen Syari'ah.

Wijayanti, T. (2017). Marketing plan dalam bisnis. Penerbit Elex Media Komputindo Kelompok Gramedia. Jakarta.

Zentes, J., Morschett, D., \& Schramm-Klein, H. (2007). Strategic retail management. Betriebswirtschaftlicher Verlag Dr. Th. Gabler GWV Fachverlage GmbH, Wiesbaden (GWV). 